\title{
The Transition to a Low-Carbon Smart Mobility in a Sociotechnical Context
}

\author{
Fotini Kehagia (iD
}

Citation: Kehagia, F. The Transition to a Low-Carbon Smart Mobility in a Sociotechnical Context. Sustainability 2021, 13, 6222. https://doi.org/ $10.3390 /$ su13116222

Received: 10 May 2021

Accepted: 26 May 2021

Published: 1 June 2021

Publisher's Note: MDPI stays neutral with regard to jurisdictional claims in published maps and institutional affiliations.

Copyright: (C) 2021 by the author. Licensee MDPI, Basel, Switzerland. This article is an open access article distributed under the terms and conditions of the Creative Commons Attribution (CC BY) license (https:// creativecommons.org/licenses/by/ $4.0 /)$.
Highway Laboratory, Division of Transportation and Construction Management, School of Civil Engineering, Aristotle University of Thessaloniki, 54124 Thessaloniki, Greece; fkehagia@civil.auth.gr

Mobility is the lifeblood of society, critical to economic and human development. Modern lifestyles and the economic growth of the last few decades have relied extensively on the fact that efficient transport enables people and goods to move quickly, over long distances and at affordable prices [1]. However, along with rapidly growing cities, a question is raised regarding the sufficient amount of transport infrastructure and whether issues of demand and capacity management should become the central concerns of decisionmakers [2].

Relentless travel is becoming increasingly associated with impacts on the environment. The extensive dependency of motorized transport on oil (oil-derived fuels account for $95 \%$ of energy consumption in transport) creates significant implications for $\mathrm{CO}_{2}$ emissions. Transport accounts for about $24 \%$ of global $\mathrm{CO}_{2}$ emissions and is one of the main sectors responsible for the increase in greenhouse gas emissions (GHGs) and the subsequent impacts on climate change, with the road sector being responsible for $74 \%$ of total transport $\mathrm{CO}_{2}$ emissions. Europe's answer to these challenges is an irreversible shift to low-emission mobility in terms of carbon and air pollutants. The ambition is clear: by the middle of the century, greenhouse gas emissions from transport will need to be at least $60 \%$ lower than they were in 1990 and be firmly on the path towards zero and air pollutant emissions from transport need to be drastically reduced [3].

The decarbonization of the transport system and emissions growth is imperative and requires a decoupling of economic growth from transport and the growth in emissions through the implementation of combined policy measures, including socioeconomic innovations, new transport technologies and a reorganization of the mobility structure [4].

The persistent aforementioned environmental challenges are tied in complex ways to prevailing economic, technological and social systems; in other words, they are systemic. These interlinkages often make it hard to affect rapid reduction; therefore, there is a need for more integrated approaches. Solutions within the present system of mobility seem insufficient to address these problems.

The sustainable mobility paradigm suggested by Banister [5] was a new alternative proposal in the mobility agenda of the complex urban environment that explores ways to address the interlinked issues of congestion, accessibility and sustainability. Beyond the main principles of sustainable travelling (substitution, modal shift, distance reduction and efficiency increase), a planning system based on personal utility and behavior change is highlighted. Lam and Head [6] analyze the meaning of sustainable urban mobility as being the "ease, convenience, affordability and accessibility of travelling to one's destination with the minimal impact on the environment and others". They propose that "accessibility and convenience can be increased with good urban design, behavioral change, advanced technology, supportive policies, economic incentives and city engagement and leadership".

In a 2015 EEA report, it is mentioned that Europe must go beyond incremental improvements in environmental performance. In order to achieve fundamental transitions or transformations in core systems, profound changes in dominant institutions, practices, technologies, policies, lifestyles and thinking have to be found $[7,8]$. 
It is difficult to address the decarbonization of the transport system with incremental improvements in the vehicle-based mobility system through gradual improvements in existing technologies and practices. A transition to a new low-carbon system, in a sociotechnical context is required. Thus, reducing the $\mathrm{CO}_{2}$ emissions from the transport sector will be addressed by deep-structural changes in transport systems. For many decades, the dominance of the automobile has created an "automobility regime" that comprises technology (vehicles), infrastructure (highways, roads, parking places, filling stations), industries (involved in production and operation), policy and established actors (policy makers, politicians, consumers, civil society, engineers and researchers) and consumer practices and patterns, cultural values and scientific knowledge. These lock-in mechanisms stabilize the existing regime, leading incumbent actors to prefer incremental changes that stay within the bounds of the existing regime [9].

We are in an era where new concepts in mobility and transport services as well as emerging technologies and digital enabled solutions have created a "governance" of smart mobility. Digital technologies, together with connectivity and automation, are transforming the traditional concepts of mobility, with a potential impact of transport decarbonization. New business models are emerging and giving rise to innovative mobility services including new online platforms for car or bicycle sharing services, freight operations, or smartphone applications offering real-time travel information and other analytics. Docherty et al. [10] describe the following as the five main innovations of smart mobility: electrification; autonomous vehicles; user-generated and user-centered information (apps, maps, devices); the shared model of vehicles (rather than the ownership of vehicles) and intelligent infrastructure (connected vehicles). The radical changes above, which are expected to dominate in the following decades, may create significant transformations in the domain of transport systems providing a personalized service mobility available on demand and a seamless system of faster, cleaner and cheaper ways for mobility to meet all of their needs [11].

New technologies, networks, institutional arrangements, actors and user practices are fundamentally challenging the rules of the existing automobility regime. Various issues emerge and old and new incumbent actors have to address the way in which the automobility system will react to these radical innovation; the way in which these new mobility patterns and technologies facilitate the transition of disruptive innovations into the operational mainstream; how new mobility patterns and solutions can be integrated in the modelling tools used for decision-making and planning; how the new mobility patterns will change mobility culture and habits; and how much behavior change is required.

When a transition to low-carbon, smart mobility finally takes place, it may bring a solution to the polluting technologies of the past and a seamless, on demand mobility but, at the same time, it may lock us unpredictably onto a new path of dependence on new technologies that are culturally problematic in other ways [12]. Mobility is associated with well-being [13]; therefore, adopting a human perspective as a guiding principle in this transition is expected to help prioritize the "right" needs as requirements [14].

This Special Issue is comprised of two papers.

Tsakalidis et al. [15], in their study, provide an overview of the European Union (EU) funded research and innovation (R\&I) and related technologies that are influencing the uptake of digital transformation in transport and identify issues and challenges from a European perspective. The study follows a two-tier approach that examines policy and legislative initiatives from the European Commission, highlighting possible challenges and enablers. Moreover, it analyzes transport technology developments in Europe, focusing on the technology maturity from EU R\&I framework programs, using the European Commission's Transport Research and Innovation Monitoring and Information System (TRIMIS). The technology analysis provides insights that aid policy decisions related to funding allocation in future R\&I framework programs.

The new worldwide challenge of the emergence of the COVID-19 pandemic is expected to drastically change the future mobility landscape, affecting the everyday life, 
practices and perceptions of the global population significantly. Vatavali et al. [16] aim to investigate the perceptions, experiences and practices of the active population regarding everyday urban life (working conditions, mobility, urban space, etc.) in the context of the first wave of the pandemic, by focusing on people who live and work in Greek cities. The data were collected using a structured questionnaire addressed to an active population. The majority of respondents declared that their personal and family lives were affected by the lockdown, with significant effects on their professional life and economic activities. As far as mobility was concerned, the majority of respondents were unwilling to change their commuting practices. Although most of the findings presented a homogenous distribution in the sample, some changes in perceptions, experiences and practices were correlated with the gender, age and family status of the respondents. The results of the analysis provide useful information to policy makers and show that it is necessary to radically rethink aspects of urban space and urban mobility in relation to the multiple problems and dynamics of the active population.

Funding: This research received no external funding.

Conflicts of Interest: The author declares no conflict of interest.

\section{References}

1. Neves, A. Transport and the Environment. In Moving towards Low Carbon Mobility; Givoni, M., Bnister, D., Eds.; Edward Elgar: Cheltenham, UK, 2013; Volume 1, pp. 166-189.

2. Banister, D.; Bonilla, D.; Givoni, D.; Hickman, R. Transport and Development-What Next? In Handbook on Transport and Development; Hickman, R., Givoni, M., Bonilla, D., Banister, D., Eds.; Edward Elgar: Cheltenham, UK, 2017; pp. 677-688.

3. EC. A European Strategy for Low-Emission Mobility; COM: Tokyo, Japan, 2016; Volume 501; COM(2016) 501 final.

4. Bonilla, D. Options for Decarbonising and Improving Energy Efficiency in the Transport Sector. In Energy Efficiency Policy and Development in South East Asia and Beyond; Thomson, E., Yeo, D., Pakiam, G., Eds.; Energy Studies Institute: Singapore, 2009; pp. 31-51.

5. Banister, D. The sustainable mobility paradigm. Transp. Policy 2008, 15, 73-80. [CrossRef]

6. Lam, D.; Head, P. Sustainable Urban Mobility. In Energy, Transport E the Environment; Inderwildi, O., King, S., Eds.; Springer: London, UK, 2012; pp. 359-371.

7. EEA. The European Environment-State and Outlook 2010: Synthesis, State of the Environment Report (SOER); European Environment Agency: Copenhagen, Denmark, 2015.

8. Tsakalidis, A.; van Balen, M.; Gkoumas, K.; Pekar, F. Catalyzing Sustainable Transport Innovation through Policy Support and Monitoring: The Case of TRIMIS and the European Green Deal. Sustainability 2020, 12, 3171. [CrossRef]

9. Geels, F. A socio-technical analysis of low-carbon transition: Introducing the multi-level perspective into transport studies. J. Transp. Geogr. 2012, 24, 471-482. [CrossRef]

10. Docherty, I.; Marsden, G.; Anable, J. The governance of smart mobility. Transp. Res. Part A 2018, 115, 114-125. [CrossRef]

11. Sumantran, V.; Fine, C.; Gonsalvez, D. Faster, Smarter, Greener. The Future of the Car and Urban Mobility; The MIT Press: Cambridge, MA, USA, 2017.

12. Sheller, M. The Emergence of New Cultures of Mobility. Stability, Openings and Prospects. In Automobility in Transitions? A Socio-Technical Analysis of Sustainable Transport; Geels, F., Kemp, R., Dudley, G., Lyons, G., Eds.; Routledge: London, UK, 2012; Volume 9, pp. 180-202.

13. Nordbakke, S.; Schwanen, T. Well-being and mobility: A Theoretical framework and literature review focusing on older people. Mobilities 2014, 9, 104-129. [CrossRef]

14. Antoniou, C.; Chaniotakis, E.; Katrakazas, C.; Tirachni, A. A better tomorrow: Towards human-oriented, sustainable transportation systems. Eur. J. Transp. Infrastruct. Res. 2020, 20, 354-361.

15. Tsakalidis, A.; Gkoumas, K.; Pekar, F. Digital Transformation supporting transport decarbonisation: Technological developments in EU-Funded Research and Innovation. Sustainability 2020, 12, 3762. [CrossRef]

16. Vatavali, F.; Gareiou, Z.; Kehagia, F.; Zervas, E. Impact of COVID-19 on urban everyday life in Greece. Perceptions, Experiences and Practices of the active population. Sustainability 2020, 12, 9410. [CrossRef] 